\title{
A representação do espaço de arquitetura por meio de dispositivos táteis: uma revisão conceitual e tecnológica
}

\author{
The representation of architectural space through haptic devices: a conceptual and \\ technological review
}

\author{
Gabriela Gonzalez Peronti \\ Universidade Federal de Pelotas, Brasil \\ ga.peronti@gmail.com
}

\author{
Adriane Almeida Borda da Silva \\ Universidade Federal de Pelotas, Brasil \\ adribord@hotmail.com
}

\author{
Mônica Veiga \\ Universidade Federal de Pelotas, Brasil \\ veiga.monicam@gmail.com
}

\begin{abstract}
This study presents preliminary results of an experiment of production and use of tactile models to explain the form of an architectural space for visually impaired people. As part of a literature review, it explores the digital manufacturing technologies such as laser cutting and 3D printing to generate representations. The review uses a case study representing a housemuseum and the experiments are based on a partnership with a school for a visually impaired people. The collaborative process has contributed to learning and explanation of multi-sensory characteristics of the constructed spaces and reinforced the need for a revision of educational processes for the architectural project regarding the habit of prioritizing essentially the aesthetic and visual aspects. The universal design concept gives grounds for each action.
\end{abstract}

Keywords: Espaço de arquitetura; Modelos táteis; Pessoa com deficiência visual; Acessibilidade; Percepção espacial.

\section{Introdução}

A experiência espacial para uma pessoa que não faz uso do sentido da visão centra-se em outras modalidades sensoriais (PEREIRA, 2016). Na cultura ocidental, a visão tem sido historicamente considerada 0 mais nobre dos sentidos (PALLASMAA, 2011). O campo da arquitetura, por meio de uma linguagem visual e estética, não foge desse panorama. Segundo VIEIRA et al. (2012), o reconhecimento do espaço arquitetônico ainda se encontra por difundir para pessoas com deficiência visual, já que "não podem apreciar as formas por suas variedades tonais". Mesmo quando uma superfície tem um potencial háptico, ou seja, que possa ser percebida por um conjunto de sentidos, incluindo o tátil, muitas vezes não está ao alcance das mãos e, suas texturas ou formas, só podem ser "tocadas com os olhos".

Frente a esta problemática, o conceito do Desenho Universal (ORNSTEIN, 2010) se faz importante para que todos se sintam contemplados, sem barreiras físicas. Além disto, 0 conceito de arquitetura multissensorial (PALLASMAA, 2011) aponta para um conjunto de características do espaço que atribuem qualidades para além da estética visual e por isto percebidas por todos os nossos sentidos.

O tato é um sentido privilegiado que permite com que as pessoas com deficiência visual apreciem e reconheçam o espaço arquitetônico (VIEIRA et al.,2012). Essa ideia é reforçada por LIMA (2011), provando a capacidade de cegos congênitos ou adventícios de compreenderem o espaço através de dispositivos hápticos, que estão se tornando cada vez mais utilizados em ambientes culturais, para esse fim, como podemos analisar em SARRAF (2013), VIEIRA et al. (2012) e PERONTI (2015).

Dentre os objetivos desse trabalho estão: ampliar referências que apoiem o desenvolvimento de representações táteis para a descrição e compreensão de um espaço arquitetônico para pessoas deficientes visuais; compreender como devem ser os modelos táteis para destacar elementos significativos, que sirvam para potencializar a experiência multissensorial para estas pessoas; produzir e validar os métodos e os tipos de modelos envolvidos; sistematizar o aprendizado para contribuir à estruturação de práticas projetuais de arquitetura que atendam aos preceitos do conceito de desenho universal.

Particularmente, há o interesse em observar como podemos associar os métodos de produção de modelos, descritos pela literatura, à experiência multissensorial que o próprio espaço oferece.

\section{Metodologia}

O estudo inclui a revisão de literatura e a experimentação de produção e uso dos recursos táteis para a descrição de uma casa-museu, uma edificação do final do século XIX, de estilo eclético tombada pelo IPHAN, em Pelotas, no Rio Grande do Sul (Figura 1).

\section{Revisão de Literatura}


A etapa de revisão bibliográfica buscou contemplar três abordagens: (1) sobre como se dá a percepção do espaço construído por pessoas deficientes visuais (PDVs); (2) acerca dos tipos de recursos táteis que estão sendo explorados para a descrição dos espaços de arquitetura; (3) sobre os objetivos associados a cada tipo de modelo tátil, e como estes estão sendo desenvolvidos, fabricados (materiais, métodos e tecnologias envolvidas) e utilizados.

Para o levantamento, foram feitas buscas em bancos de dados digitais a partir das seguintes palavras-chave: Arquitetura Multissensorial; Espaço de arquitetura; Modelos táteis; Pessoa com deficiência visual; acessibilidade; percepção espacial; Tátil; Tecnologia Assistiva; Fabricação Digital; impressão 3D. Os bancos acessados até o momento foram o Cumincad e o Google acadêmico, sendo selecionados apenas os trabalhos que abordavam o uso dos modelos táteis como representação do espaço arquitetônico.

\section{Sobre a percepção dos recursos multissensoriais no espaço construído}

HERSSENS \& HEYLIGHEN (2009) compararam a percepção visual à háptica. Avaliaram ambientes através da percepção de pessoas cegas, procurando identificar as qualidades multissensoriais de espaços construídos. As autoras afirmaram que a arquitetura é experenciada de maneira multissensorial e que cada indivíduo percebe 0 espaço à sua maneira. Para fazerem tais afirmações, realizaram experimentos com indivíduos voluntários nascidos cegos, explicando o propósito de que estes não recorressem nenhum resíduo visual de imagem ou de memória, focando apenas nos outros sentidos. Em HERSSENS \& HEYLIGHEN (2007), já chamavam a atenção para o fato de que o processo de projeto de arquitetura geralmente foca apenas na representação visual, deixando de lado os outros sentidos. O estudo afirma que esta postura faz parte do comportamento do arquiteto, que se utiliza de uma linguagem predominantemente visual.

PALLASMA (2011) também aponta o processo projetual do arquiteto e critica o ocularcentrismo praticado nos últimos anos. Portanto, defende a arquitetura dos sentidos, uma arquitetura multissensorial. Exemplifica como a arquitetura nos toca e ativa todos os nossos sentidos e, por consequência, nossas emoções, imaginação e sonhos. Isto é feito destacando a importância da escolha de materiais, da entrada da luz, da maneira com que o vento entra e nos toca.

\section{Sobre os tipos de recursos táteis}

VIEIRA et al. (2012) registram três casos de uso de modelos táteis representativos de espaços de arquitetura. Um deles possui representações em alto relevo de elementos arquitetônicos em vista ortográfica, associados a áudio-guia e escritos em braille; outro apresenta uma maquete tátil do edifício localizada no espaço urbano de seu entorno e o terceiro disponibiliza para o toque elementos arquitetônicos originais do edifício. Neste trabalho, também é abordada a dificuldade da manutenção da acessibilidade a estes recursos, referindo-se, especificamente, a um caso em que a maquete é feita de bronze, exposta em uma área externa, exigindo cuidados de limpeza constante para possibilitar o toque.

SARRAF (2013) apresenta um panorama de trinta e oito museus e espaços culturais, entre a América do Norte, Europa e Brasil, que contemplam recursos dirigidos às pessoas com deficiência. Entretanto, destaca que apenas nove deles apresentam dispositivos táteis focados na representação da arquitetura. Dentre eles, cinco possuem mapas táteis de localização; um tem uma maquete tátil do edifício que abriga o próprio museu; dois apresentam réplicas ou peças originais de elementos do patrimônio; um tem em sua coleção maquetes de monumentos arquitetônicos famosos, além de sinalização sonora durante todo o percurso e o último inclui um paisagismo multissensorial, com diferentes cheiros e texturas. Este mesmo estudo subsidia uma análise sobre tipos de materiais empregados para o desenvolvimento destes recursos.

Descreve a infraestrutura disponibilizada pelo Museu Tiflológico da Organização Nacional de Cegos da Espanha, ONCE, em Madrid. Destaca que o acervo deste Museu contém maquetes táteis de monumentos arquitetônicos famosos, como a Torre Eiffel, em materiais variados como, mármore, madeira e metal. Em VIEIRA et al. (2012) também se encontra este tipo de referência, quando registra que a maquete tátil da Torre de Belém, em Lisboa, é de bronze.

Em PERONTI et al. (2015) registraram-se resultados parciais de um referencial teórico sobre os tipos de recursos táteis (mapas e modelos táteis) e suas diferenças, utilizados para atribuir acessibilidade para a compreensão dos espaços de instituições culturais. O estudo abrangeu a análise de nove instituições, observando-se os tipos e a localização dos recursos empregados.

Os estudos referidos indicam uma diversidade de materiais utilizados para os recursos táteis para traduzir o espaço de arquitetura, sem indicações de padronizações.

\section{Sobre o processo de Desenvolvimento e Fabricação}

DE BEM \& PUPO (2015) identificaram quatro casos de produção de mapas ou maquetes táteis em instituições de ensino, diferenciando três tipos de tecnologias empregadas para atribuir volumetria: Impressão 3D colorida, Sinterização Seletiva a Laser e Corte a laser somado à impressão 3D baseada em pó de celulose.

Em BORDA et al (2012) e VEIGA et al (2013), tem-se o registro da estruturação de um método batizado como "Adição Gradual de Informação" (AGI). O método consiste em considerar a necessidade de desmembrar informações complexas para o tato, gerando camadas de informação. Propõe a descrição de elementos mínimos de maneira isolada para logo conectar com a complexidade do todo a ser representado. Os recursos táteis passam a compor uma narrativa própria e necessariamente conectada com outros meios como o da audiodescrição. Este método foi elaborado para a descrição de fotografias. 
DALLA VECCHIA et al. (2015) apresentam casos de produção de representações táteis para a compreensão de edifícios e elementos arquitetônicos de interesse patrimonial. As representações foram produzidas através de impressão 3D e corte a laser, tomando como referência o processo de Adição Gradual de Informação, referido anteriormente. Os modelos foram avaliados positivamente por voluntários deficientes visuais. Os materiais utilizados foram o PLA para a impressão 3D por FDM e a madeira (MDF) para o corte à laser.

SPERLING et al. (2015), registra uma experiência didática, que explorou um processo de projeto de habitação com e para pessoas com deficiência visual. Utilizaram-se de modelos, plantas e mapas táteis, avaliando a conveniência de empregar diferentes tipos de materiais e de processos, incluindo a fabricação digital (placas de MDF em máquina de corte a laser). A atividade resultou em seis projetos realizados em grupo, que buscaram estratégias para que os espaços resultantes ativassem os sentidos, como o emprego de grandes aberturas, possibilitando a recepção do calor solar (tato). O trabalho reconheceu a importância de usar as três linguagens (planta, mapa e maquete tátil) para a tradução do processo e do espaço de arquitetura proposto. Também foi apontada a facilidade da técnica de fabricação digital, que apesar de ser limitada em relação à representação de texturas, proporcionou constância material e dimensional relevantes para a legibilidade do recurso.

Em meados dos anos 2000, o comitê da ISO definiu uma série de diretrizes para a construção de representações táteis (Fourney \& Carter, 2005). Entre elas, existe a instrução de que formas muito complexas devem ser simplificadas para que possam ser melhor percebidas pelo tato._A ISO recomenda também fornecer informações de navegação para evitar que o usuário se perca no espaço háptico. Além disso, ressalta a importância do uso da multimídia, para complementar o toque, destacando que, em casos de representações de formas complexas, o uso da audiodescrição torna-se fundamental.

\section{Experimentação com a produção e uso de modelos táteis}

O processo de revisão está sendo acompanhado por procedimentos de experimentação, reproduzindo-se os tipos de modelos, métodos e tecnologias identificadas, especialmente buscando-se transpor os processos de produção artesanais para a fabricação digital, por corte a laser e por impressão 3D por FDM.

Esses experimentos são realizados no âmbito de um projeto de extensão intitulado $O$ Museu do Conhecimento para Todos: inclusão cultural de pessoas com deficiência em museus universitários, da Universidade Federal de Pelotas (UFPel). Esse projeto tem o objetivo de configurar os espaços museais desta Universidade de acordo com o conceito de Desenho Universal. Atualmente o Projeto está centrado ao espaço que abriga o "Museu do Doce", que conta a história de uma atividade tradicional da cidade. Além disso, ao espaço está atribuído o conceito de casa-museu, sendo a história da casa e de sua arquitetura também protagonistas na exposição do Museu.
Figura 1: Fotografia da Casa-Museu: Museu do Doce, Pelotas - Brasil.

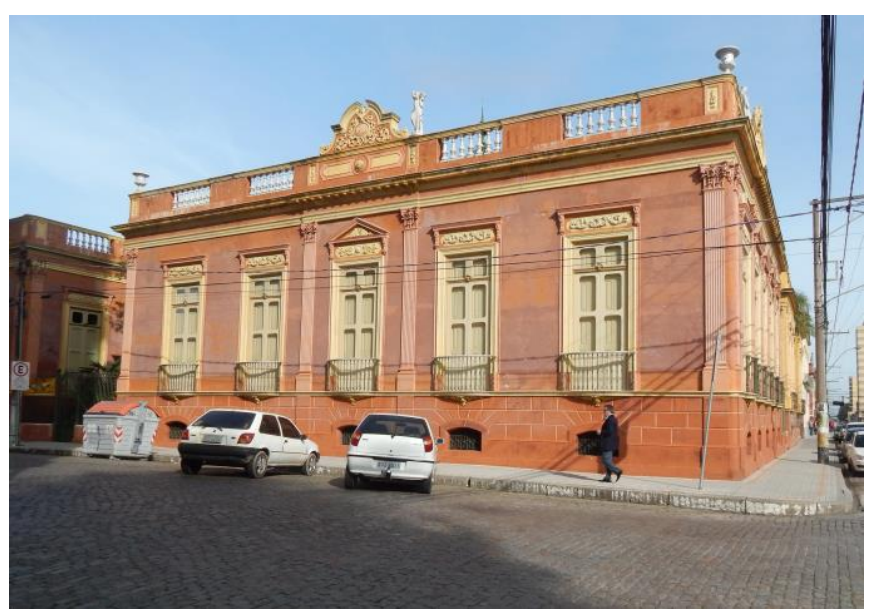

Fonte: Acervo dos autores.

A experiência de produção e uso dos modelos físicos, até então incluiu:

1) Em um primeiro momento, a produção de um mapa tátil e promoção da primeira visitação da escola Luís Braille, uma instituição de ensino dedicada às pessoas com deficiência visual.

2) Reflexão sobre a experiência de uso do mapa tátil e sobre as percepções explicitadas pelos visitantes.

3) Processo de produção dos modelos tridimensionais.

4) Reflexão sobre a experiência do conjunto de representações produzido e sobre as percepções explicitadas pelos visitantes.

5) Sistematização dos resultados

\section{Resultados}

O primeiro resultado foi a produção de um híbrido de mapa e planta tátil (figura 2). Compreendeu uma planta baixa em relevo do primeiro pavimento da casa-museu com indicação do percurso (removível) a ser feito na visita. Para o desenvolvimento desse mapa utilizou-se como base a documentação técnica (plantas baixas, cortes e fachadas), disponibilizada pela Secretaria de Cultura de Pelotas (SECULT), e a revisão da literatura estudada. Esse recurso foi produzido com placas de madeira (MDF) através da tecnologia de corte a laser. A representação não apresentava informações em braile, tendo sido produzida para apoiar um processo de mediação para explicar a distribuição espacial dos cômodos que compõem a edificação e situar o visitante no trajeto proposto pela visitação.

Promoveu-se a visitação da escola Luís Braille. Os mediadores contaram a história da casa, enquanto sugeriam o toque em alguns elementos arquitetônicos para que 0 visitante percebesse a diversidade de materiais com suas formas, temperaturas e texturas. A mediação teve início na parte externa da casa, e depois de passar pelo hall de entrada, os visitantes eram conduzidos à Sala da Claraboia, 
um espaço de distribuição, iluminado zenitalmente, no centro do corpo principal da casa, totalmente rodeado pelos cômodos. Por conta dessas características, esse espaço tem a incidência da energia do sol sobre a pele do visitante e proporciona uma luz particular, um som próprio deste interior da casa, sem interferência do barulho da rua, podendo-se perceber também a ventilação que se cruza pela disposição de todas as portas que o contornam provocando diferentes sensações. Durante a visita esse espaço chamou a atenção dos visitantes, os quais explicitaram as percepções sensoriais com entusiasmo.

Figura 2: Modelo Tátil da planta baixa da Casa-Museu: Museu do Doce, Pelotas - Brasil.

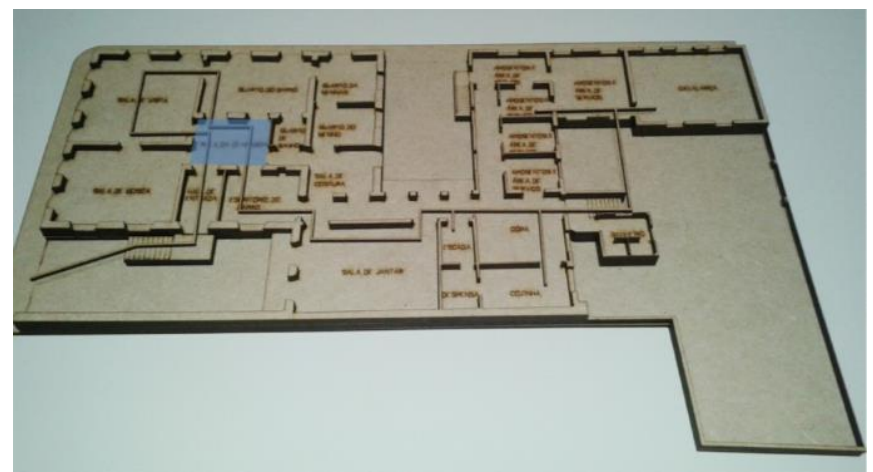

Fonte: Acervo dos autores.

O modelo tátil foi disponibilizado e ficou localizado na Sala da Claraboia (local indicado na figura 2). Este recurso foi considerado apropriado pelos visitantes. Entretanto, evidenciou-se a necessidade de construção de uma narrativa mais ampla, exigindo outras camadas de informação. Uma delas para descrever a volumetria simplificada de toda a edificação e outras para melhor explicar as sensações percebidas junto ao espaço da clarabóia.

A partir destes registros, passou-se a planejar diferentes camadas de informação: modelos que facilitassem a estruturação de narrativas para explicar os tipos de elementos e resoluções projetuais desta casa-museu responsáveis por promover as sensações multissensoriais ali experenciadas.

Foram então encaminhados: o aprimoramento do mapa tátil, a maquete da volumetria da casa e modelos da claraboia. Para o aprimoramento das representações estudou-se como inserir o recurso sonoro, como demonstrado em d'ABREU E BERNARDI (2009), identificado por BEM E PUPO (2015). Estabeleceu-se uma parceria com alunos da Ciência da Computação e Engenharia de Controle e Automação da UFPel, para o desenvolvimento deste recurso. A Figura 3 ilustra o resultado, observando-se a necessidade de gerar uma base para incluir um sistema de som digitalizado, descrito em CRUZ, ROSSI e BORDA, 2016. Está em desenvolvimento a maquete da volumetria da casa a fim de tornar a tradução do espaço da casa-museu mais completa, como defendido por SPERLING et al. (2015).
Figura 3: Modelo Tátil/Sonoro da Casa-Museu: Museu do Doce, Pelotas - Brasil.

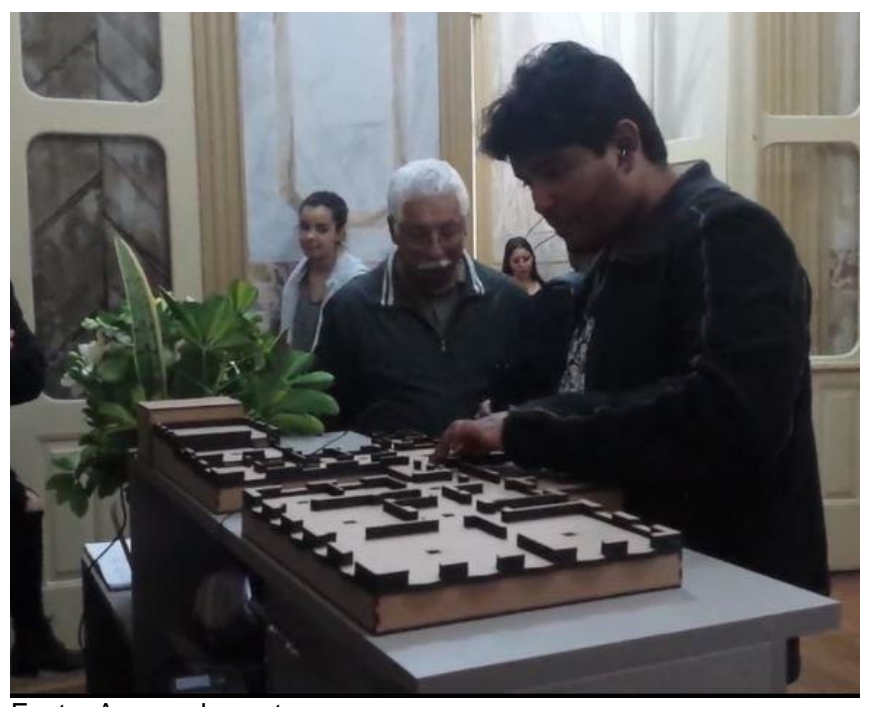

Fonte: Acervo dos autores

Para a representação da claraboia (Figura 4), como registrado em PERONTI et al (2016), foi gerado um conjunto de representações em diferentes escalas, como sugere o método da Adição Gradual da Informação (AGI).

Figura 4: Fotografia da Claraboia (externa e interna) da Casa-Museu: Museu do Doce, Pelotas - Brasil.

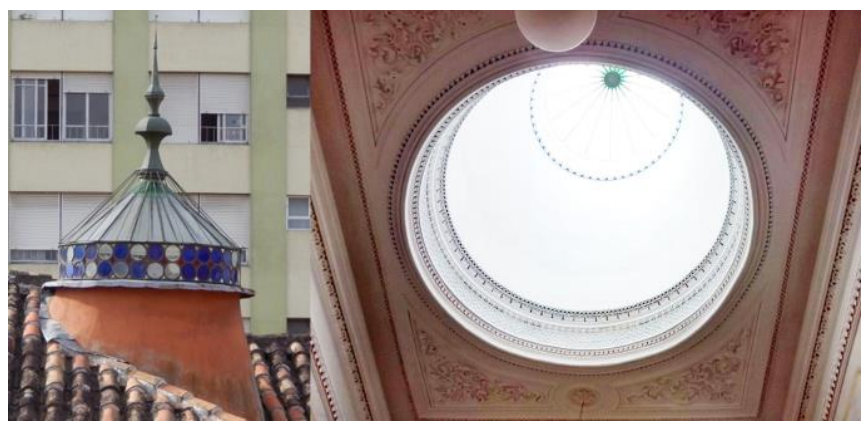

Fonte: Acervo dos autores.

Inicialmente foram produzidos dois modelos da claraboia, fabricados por impressão 3D, em PLA (modelos à esquerda e ao centro da figura 5). Estes modelos se mostraram inadequados, o primeiro por explicar apenas a forma externa do elemento de cobertura da claraboia e o segundo ainda pela fragilidade perante o toque. $O$ terceiro (à direita da mesma figura) avançou em relação à resistência ao toque, representando detalhes do elemento e retratou com precisão as suas proporções. Deve-se destacar que para esta representação foi possível contar com as informações de uma nuvem de pontos obtida pelo escaneamento a laser deste elemento. As outras duas representações haviam sido realizadas a partir de uma documentação obtida por levantamento tradicional, contendo distorções da forma. 
Figura 5: Modelos Táteis da Claraboia da Casa-Museu: Museu do Doce, Pelotas - Brasil.

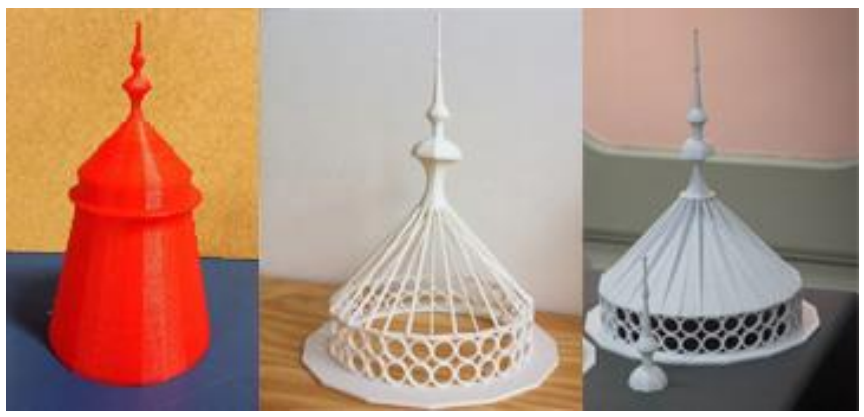

Fonte: Acervo dos autores.

A partir de uma representação precisa de toda a superfície interna e externa que conforma o elemento da clarabóia foi gerado o conjunto de modelos para traduzir a geometria do ambiente. A imagem da esquerda da Figura 6 refere-se à nuvem de pontos utilizada. Esta nuvem é um tipo de representação digital constituído por um conjunto de pontos, sobre os quais são conhecidas as suas posições no espaço tridimensional, todas elas relativas a um mesmo sistema de coordenadas. Ao centro da mesma figura está a imagem da representação digital que tomou como referência a nuvem de pontos, configurando um modelo que explica o pé direito da sala, a altura em que se situa a claraboia em relação à figura humana. A imagem da direita da Figura 5 ilustra cada uma das partes que compõem a narrativa do espaço, todas impressas em 3D.

Figura 6: Modelos Táteis do espaço da Claraboia da CasaMuseu: Museu do Doce, Pelotas - Brasil.
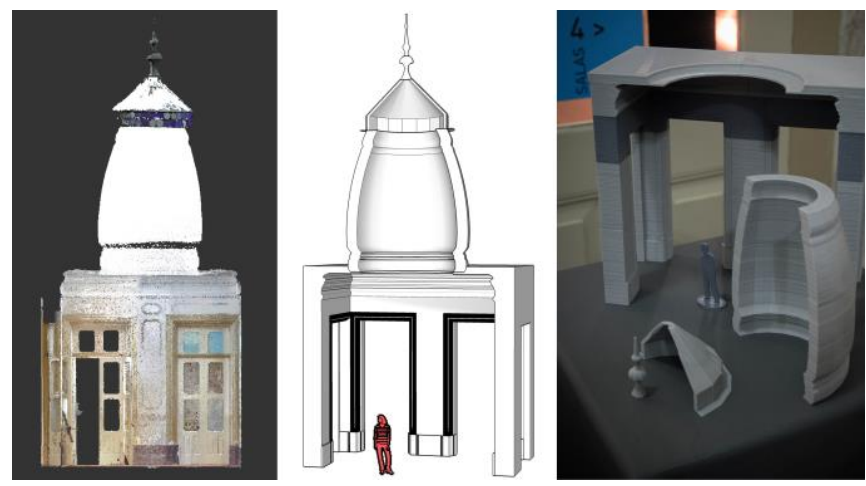

Fonte: Acervo dos autores.

Ainda em desenvolvimento está a impressão da outra metade da representação deste elemento para que se tenha a camada da informação do todo, incluindo um esquema dos estuques presentes na parte interna da cúpula da claraboia e no teto da sala.

Todas estas representações já estão sendo testadas, em uma exposição de caráter permanente do Museu. Os feedbacks dos visitantes com deficiência visual estão sendo registrados pelos próprios mediadores do Museu. Já se tem o registro da percepção, de pessoas com deficiência visual, sobre a evolução dos recursos, ao passar para o mapa tátil/sonoro e ao disponibilizar modelos tridimensionais dos elementos da casa.

\section{Discussão}

Este trabalho dedicou-se à revisão de estudos relacionados à representação tátil do espaço arquitetônico para apoiar um processo de produção destas representações junto a uma casa-museu. Como um dos resultados desta revisão, a produção destas representações passou a considerar especialmente 0 conceito de arquitetura multissensorial. Obtiveram-se resultados capazes de reforçar a validação do método da adição gradual da informação.

Registra-se, como um dos aprendizados mais significativos advindos deste estudo, a percepção do quanto o esforço em compreender como estruturar uma narrativa sobre um espaço de arquitetura, para pessoas com deficiência visual, tem acrescentado para o aprendizado específico de arquitetura. Aprendizado para o exercício projetual, no momento em que se passa a identificar e explicitar os recursos arquitetônicos capazes de provocar sensações, como iluminação, ventilação, sonoridades. A estas sensações não estamos habitualmente sensíveis, reforçando o que HERSSENS \& HEYLIGHEN (2009) observaram junto à prática profissional dos arquitetos: Estamos treinados fundamentalmente para o visual.

\section{Considerações Finais}

Considera-se possível afirmar, a partir das percepções aqui registradas, que as narrativas que explicam os espaços de arquitetura podem promover nos visitantes, deficientes visuais, a construção de critérios para a análise da qualidade de tais espaços. Mais do que isto, e de interesse de uma instituição museal, que a experiência seja educativa e significativa ao ponto de se estabelecer na memória, mesmo que sem 0 apelo visual ao qual a arquitetura maioritariamente tem se pautado. A experiência, envolvendo um ambiente acadêmico de arquitetura, provoca reflexões e motivações para avançar no uso do conceito de arquitetura sensorial.

\section{Agradecimentos}

Ao Engenheiro Diego Sacco Silveira, da Empresa Triangular/Pelotas, RS, pela disponibilização gratuita da nuvem de pontos da edificação abordada neste trabalho.

\section{Referências}

Bernard, N.; d'Abreu, J. V. V.; Kowaltowski, D. C. C. K. (2009). Orientação espacial no Campus da Unicamp: Diretrizes para o desenvolvimento de um mapa de uso tátil e sonoro como ferramenta de auxílio ao percurso do usuário com deficiência visual. $X$ ENCONTRO NACIONAL e ENCONTRO NACIONAL e VI ENCONTRO LATINO AMERICANO de C O N F O R T O N O A M B I E N T E C O N S T R U Í D O. Natal, 16 a 18 de setembro de 2009. 
Borda, A.; Veiga, M.; Nicoletti, L.; Michelon, F. (2012). Descrição de Fotografias a partir de modelos táteis: ensaios didáticos e tecnológicos. $3^{\circ}$ Seminário Internacional Museografia e Arquitetura de Museus conservação e técnicas sensoriais, [s.I.: s.n.], 2012.

Cruz, G.; Rossi, M.; Borda, A. (2016). Desenvolvimento tecnologico para sonorização de um mapa tátil: circuito e programa. XXV CONGRESSO DE INICIAÇÃO CIENTÍFICA. Universidade Federal de Pelotas. Pelotas - RS.

Dalla Vecchia, L.F.; Borda, A; Pires, J.; Veiga, M.; Vasconselos, T.; Borges, L. (2015) Tactile models of elements of architectural heritage: from the building scale to the detail The next city - New technologies and the future of the built environment [16th International Conference CAAD Futures 2015. Sao Paulo, July 8-10, 2015. Electronic Proceedings/ ISBN 978-85-85783-53-2] Sao Paulo, Brazil, July 8-10, 2015, pp. 434-446.

De Bem, G.; Pupo, R. (2015). Imprimindo o espaço para as pessoas com deficiência visual: uma revisão sistemática. In: SIGRADI 2015. Florianópolis, Universidade Federal de Santa Catarina, nov. 2015. Disponível <http://papers.cumincad.org/data/works/att/sigradi2015_3.370.pdf>. Acesso em: 16 maio. 2016.

Fourney, D.; Carter, J. (2005). Initiating Guidance on Tactile and Haptic Interactions:ISO 9241-920. Canada, 2005. Disponível em: http://userlab.usask.ca/GOTHI/Fourney\%20\%20Guidance.pdf. Acesso em Maio de 2012.

Herssens, J.; Heylighen, A. (2007). Haptic architecture becomes architectural hap. Disponível em: http://www.nordiskergonomi.org/nes2007/CD_NES_2007/papers/A34 _Herssens.pdf. Acessado em: junho de 2016.

Herssens, J.; Heylighen, A. (2009). Haptics and vision in arquitecture: designing for more senses. Conference Sensory Urbanism. University of Strathclyde, Glasgow, UK.

Lima, F. J. (2011). Breve revisão no campo de pesquisa sobre a capacidade de a pessoa com deficiência visual reconhecer desenhos hapticamente. Revista Brasileira de Tradução Visual, Vol.6, № 6.

Milan, L. (2008). Maquetes táteis: infográficos tridimensionais para a orientação espacial de deficientes visuais. Acessado em 10 de jul. $2015.2 \quad$ Online. Disponível em: http://www.fec.unicamp.br/ parc/vol1/n2/vol1-n2. Acessado em: junho de 2008.

Ornstein, S.W. (org.). Desenho universal: caminhos da acessibilidade no Brasil. São Paulo: Annablume, 2010.
Pallasma, J. Os olhos da pele: Arquitetura e os sentidos. Trad: Alexandre Salvaterra. Porto Alegre: Bookman, 2011. 68p.

Pereira, C.M. Conversa com Carlos Mourão Pereira sobre o espaço e percepção de um arquiteto cego. Disponível em:http://hugopeepbox.com/2016/02/15/uma-conversa-com-carlosmourao-pereirasobre-espaco-e-percecao-com-um-arquiteto-cego/. Acessado em: abril de 2016.

Peronti, G.G.; Veiga, M; Borges, L.F.; Parker, G.; Borda, A. (2015). Mapas e Maquetes Táteis utilizados por instituições culturais: Estudo de caso. II CONGRESSO DE EXTENSÃO E CULTURA. Universidade Federal de Pelotas. Pelotas - RS.

Peronti, G.G.; Veiga, M.; Borda, A. (2016). A extensão da percepção: Uma experiência com a produção de modelos táteis para descrever a ambiência gerada pela claraboia do casarão 8 , Pelotas-RS. III CONGRESSO DE EXTENSÃO E CULTURA. Universidade Federal de Pelotas. Pelotas - RS.

Pietrykoswka, J. (2015). Physical Models of Built Heritage - Making Architecture More Comprehensive to the Blind and Visually Impaired. In: ENVISIONING ARCHITECTURE: IMAGE, PERCEPTION AND COMMUNICATION OF HERITAGE. Lodz, PolandLodz University of Technology, out. 2015.2 Disponível em: <http://papers.cumincad.org/data/works/att/eaea2015_t2_paper12.pd f>. Acesso em: 10 maio. 2016

Sarraf, V.P. (2013). A Comunicação dos sentidos dos sentidos nos espaços culturais brasileiros: estratégias de medições e acessibilidade para as pessoas com suas diferenças. 235p. Tese de Doutorado - Programa de Pós-graduação em Comunicação e Semiótica, Pontifícia Universidade Católica de São Paulo.

Veiga, M.; Borda, A.; Michelon, F.; Lebedeff, T. (2013). Atribuição de Acessibilidade à Fotografia através da Restituição e Desconstrução da Tridimensionalidade. XVII CONFERENCE OF THE IBEROAMERICAN SOCIETY OF DIGITAL GRAPHICS, 17., Valparaíso, Chile, 2013. SIGRADI: Knowledge-based Design 2013, Universidad Técnica Federico Santa María, 2013.p.449.

Vieira, A., Aguiar, J., Pedro, J. B. (2012). O que os olhos não vêem mas o coração sente: $O$ reconhecimento do espaço arquitetónico por invisuais. In: SEMINÁRIO INTERNACIONAL DA FACULDADE DE ARQUITETURA E URBANISMO: Espaços Narrados: a construção dos múltiplos territórios da língua portuguesa. São Paulo: FAU/USP,2012 p.1486.

Voigt, A.; Martens, B. (2006). Development of 3D Tactile Models for the Partially Sighted to Facilitate Spatial Orientation. In: ECAADE 24: COMMUNICATING SPACE(S). Volos, Greece: University of Tessaly, 2006. Disponível em: <http://papers.cumincad.org/data/works/att/2006_366.content.pdf>. Acesso em: 12 maio. 2016. 